\title{
Federalismo e bons governos: uma análise política da gestão fiscal dos municípios
}

\author{
Clóvis Alberto Vieira de Melo \\ Saulo Santos de Souza \\ Washington Luís de Sousa Bonfim
}

\section{Introdução}

Um dos aspectos mais abordados na literatura é o grau de autonomia municipal na formulação e implementação de políticas públicas. Costa, Cunha e Araújo (2010) observam que os municípios brasileiros foram elevados à condição de entes federativos autônomos pela Constituição de 1988. O propósito foi o de tornar sua autoridade política soberana e independente dos demais níveis de governo. Isso acabou por gerar nas relações intergovernamentais uma fragmentação de poder mediante a qual os atores políticos locais passaram a gozar de espaço de manobra próprio, podendo, até certo ponto, influenciar na capacidade de governar dos níveis superiores.

Por outro lado, Souza (1996) lembra que o modelo de federalismo adotado no Brasil implica graus variados de cooperação política e financeira entre a União e as demais esferas de poder, isso porque poucas competências constitucionais exclusivas foram atribuídas aos estados e municípios. A despeito desse fato, o federalismo brasileiro tem sido marcado atualmente por políticas públicas federais que se impõem às instâncias subnacionais (Souza, 2005).

Do ponto de vista tributário, os municípios brasileiros foram os grandes beneficiários da descentralização decorrente da reforma constitucional de 1988, que Ihes concedeu maior liberdade para arrecadar e alocar recursos próprios (Souza, 1996). Tótora e Chaia (2002) notam, entretanto, que, mesmo recebendo mais recursos provenientes de transferências constitucionais, os municípios não compartilham condições semelhantes para a provisão das políticas que eram anteriormente de responsabilidade da União ou dos estados. Esses autores também sugerem que o Fundo de Participação dos Municípios (FPM), que passou a compor boa parte da receita municipal, pouco contribui para reduzir as diferenças intermunicipais em termos de capacidade institucional, dado que os entes recipientes não partem de um mesmo patamar. Ademais, embora os governos municipais se submetam ao mesmo conjunto de normas legais que regem a gestão dos recursos públicos, Souza (2005) corrobora a ideia de que a capacidade dos governos locais de arrecadar e aplicar seus recursos na implementação de políticas é amplamente diferenciada. Ou seja, a gestão municipal depende também de fatores alheios à arena tributária. 
Para Borges (2010), a democracia brasileira se caracteriza por um federalismo descentralizado que permite ampla atuação dos atores e instituições subnacionais na formulação e implementação de políticas públicas. Kerbauy (2001) acrescenta que essa delegação de poder decisório para os municípios tem duas importantes implicações: primeiro, os prefeitos têm maior responsabilidade na provisão de bens e serviços públicos; segundo, as prefeituras buscam adotar mecanismos de modernização gerencial da gestão pública. No âmbito político, esses dois efeitos da descentralização impactam de forma substancial as estruturas do poder local.

Embora haja governos municipais que demonstrem comprometimento com melhorias no atendimento das demandas dos cidadãos e, em última análise, com a eficiência da gestão por motivos meramente programáticos ou pela qualidade moral dos gestores, ou pela combinação de ambos, Arretche (2003) assevera que não se pode garantir a responsabilidade dos governos locais com a gestão exclusivamente com base nesses fatores. Mais que isso, a qualidade da ação dos governos locais está relacionada, em boa medida, aos incentivos incidentes sobre seus governantes e aos controles a que eles estão submetidos, os quais provêm do desenho institucional das políticas. Em outras palavras, não há quaisquer garantias vinculadas ao grau de autonomia dos governantes locais que os levem a administrar com eficiência. O corolário é que a autonomia dos governos municipais no campo das políticas públicas, segundo Arretche, "pode produzir resultados opostos aos esperados pelos defensores mais otimistas da descentralização" (2003, p. 334).

Nesse contexto, após quase 25 anos de políticas descentralizadoras consagradas pela Constituição de 1988, é importante perguntar: até que ponto esse novo posicionamento institucional federativo foi capaz de gerar "bons governos" no âmbito municipal? Descentralização é aqui entendida como transferência de poder decisório dos entes superiores para os governos locais (Kerbauy, 2001). Ou seja, está associada ao grau de autonomia federativa dos municípios, inclusive na área fiscal (Arretche, 1999). Por outro lado, entenda-se por bons governos as gestões que possuem equilíbrio fiscal em suas contas e que conseguem atender adequadamente às demandas dos cidadãos (Andrews, 2010).

Para responder a essa questão pesquisamos o universo das gestões locais brasileiras, em busca de padrões nessa esfera e verificando quais variáveis políticas poderiam influenciar na qualidade dos governos locais. Além desta introdução e das conclusões, este artigo divide-se em cinco seções, quais sejam: "Questões do federalismo na literatura nacional"; "Ainda na literatura: a política das políticas públicas"; "Aspectos metodológicos"; "Padrões de gestão fiscal nos municípios brasileiros"; e, por último, "Fatores políticos que condicionam bons governos", que discutem as questões teóricas, metodológicas, e os achados do estudo. 


\section{Questões do federalismo na literatura nacional}

A literatura comunga do entendimento de que a rede de proteção social no Brasil vem sendo profundamente modificada a partir da implantação de programas de descentralização que vêm aos poucos delegando um conjunto substancial de atribuições de gestão para os governos municipais. Como veremos, os desdobramentos dessa descentralização no federalismo brasileiro assumem feições distintas em cada área específica das questões sociais, com destaque para a saúde e a educação, dado que a sistemática descentralizadora de políticas públicas imputou aos municípios grandes responsabilidades no atendimento de demandas nessas áreas.

No caso da educação, o artigo 211 da Constituição Federal estabelece que "a União, os Estados e os Municípios organizarão em regime de colaboração seus sistemas de ensino". Estando a educação, por essa razão, num campo de provisão concorrencial, a prestação de seus serviços cabe a todos os níveis federativos. Para Gouveia (2009), entretanto, tamanho é o grau de descentralização do sistema educacional brasileiro que a avaliação de efetividade das políticas educacionais requer que se priorize o contexto municipal, muito embora este seja balizado pelas decisões na esfera federal. No caso da educação infantil e fundamental em particular, a prioridade de atendimento é das cidades, o que gera possibilidades de exercício do poder local sobre o formato das políticas, por um lado, e disparidades na qualidade da gestão, por outro.

Quanto à administração da saúde pública no Brasil, a Constituição Federal caracteriza o SUS como um sistema descentralizado e hierarquizado. Assim, é o governo federal que formula e financia a política nacional de saúde, além de coordenar as ações intergovernamentais de cooperação técnica e financeira nessa área. Os estados, por sua vez, desempenham funções semelhantes em relação aos municípios, a quem cabe a responsabilidade final de prestar atendimento à população. Por esse sistema, embora o governo federal regule as decisões dos governos subnacionais, há para os estados e municípios a prerrogativa de opinar na formulação das políticas destinadas a sua área de jurisdição, ou mesmo de não aderir à política estabelecida no nível federal. Via de regra, a adesão é obtida por conta dos incentivos e sanções presentes no sistema de relações intergovernamentais (Souza, 2005), o que acaba condicionando grande parte das decisões políticas tomadas no nível subnacional, levando à eventual implementação dessas políticas pelos municípios.

Ademais, a Lei federal 8.080/90, ao passo que ampliou as funções alocativas e regulatórias da União na arena da saúde, ampliou também a responsabilidade dos municípios de planejar e executar os serviços correspondentes. Os governos locais são desde então os principais provedores dos serviços de saúde no Brasil. Souza (2005) lembra, porém, que a provisão desses serviços depende de recursos federais e sujeita-se a regras que visam a garantir padrões mínimos de gestão. Paradoxalmente, a municipalização da saúde acabou por reduzir os conflitos entre os governos locais gerados pela disputa por recursos da União. Isso se deve ao fato de que as relações que 
se estabeleceram entre o governo central e os municípios tornaram-se cada vez mais frequentes com a implementação local dos programas federais de saúde. Ainda assim, Arretche (2003) não vê no federalismo brasileiro mecanismos que assegurem responsabilidade e eficiência na gestão local das políticas de saúde pública.

Em suma, enquanto a autoridade sobre a definição das diretrizes gerais das políticas sociais é centralizada, sua implementação é descentralizada. Isso tem gerado consequências no campo eleitoral. A principal delas é que os atores políticos nos níveis federal e subnacional têm competido entre si por um mesmo reduto de eleitores ao reivindicar os resultados positivos dos programas sociais implantados em um dado território.

Além disso, conforme argumenta Borges (2010), os governos subnacionais competem com políticas similares ofertadas pelo governo federal ao buscar o apoio do eleitorado por meio de seus próprios programas sociais. Teriam, então, esses elementos políticos peso decisivo sobre a qualidade da gestão das políticas públicas nos municípios brasileiros? As seções que se seguem fazem breve inventário dos determinantes do desempenho local mencionados na literatura, particularmente as instituições, a política e a capacidade de financiamento das políticas públicas.

No que é relativo a regras e controles, o nível de comprometimento dos governos com a eficiência na gestão pública está associado aos incentivos a que os governantes estão sujeitos. Para Arretche (2003), são em grande medida as instituições, a saber, desenhos de política, regras legais e normas sociais, que propiciam os incentivos que moldam o comportamento dos políticos em cargos de gestão. Dentre essas instituições, destaque é dado às regras que envolvem a formulação e implementação das políticas públicas. São as regras do processo decisório, das arenas institucionalizadas de representação de interesses, do monitoramento da política com mecanismos de controle e punição, etc., as quais fornecem os incentivos aos atores políticos locais.

A autonomia local para a gestão de políticas é, dessa forma, balizada pelos incentivos institucionais, o que afeta a liberdade dos governantes em implementar decisões exclusivamente de acordo com seus próprios interesses. Concordam com isso Motta e Moreira (2007), para quem o incentivo à melhor gestão dos prefeitos relacionase, entre outros elementos, ao grau de controle institucional e ao benefício eleitoral do governante. O controle institucional pode estar associado à filiação partidária dos prefeitos e ser exercido por intermédio de conselhos municipais setoriais, os quais, por sua vez, garantem a participação social nas decisões de políticas. As instituições favorecem, por esse veio, o bom governo, dado que os interesses dos governantes nem sempre se alinham ao interesse público e ao bem-estar social.

Contudo, o desempenho do governo municipal depende não apenas dos incentivos eleitorais do prefeito, mas também da capacidade do município de financiar os gastos públicos, colocando o orçamento a serviço de uma melhor qualidade de vida para os cidadãos. Por outro lado, a necessidade de financiamento das políticas públicas dá origem a uma disputa pela ampliação de recursos à disposição das prefeituras. Segundo 
Gouveia (2009), a disputa em torno de recursos escassos pode resultar no aumento da eficiência na aplicação dos recursos orçamentários, ao passo que Motta e Moreira (2007) preveem o efeito contrário: quando há uma proporção significativa de recursos públicos, oriundos de receitas próprias ou transferências, há incentivos para que os gestores incorram em risco moral, ou seja, no uso inapropriado ou ineficiente desses recursos.

Para Sakurai e Filho (2007), a performance fiscal dos prefeitos afeta substancialmente seu desempenho nas urnas, visto que suas chances de serem reeleitos crescem à medida que se eleva a despesa orçamentária. Essa despesa, por sua vez, depende da obtenção de transferências correntes e de capital dos governos federal e estadual. A lógica por trás desses resultados é que um maior volume de repasses intergovernamentais obtido pelos prefeitos tende a ser avaliado de forma positiva pelo eleitorado por sinalizar a competência da gestão local em canalizar recursos em benefício do município. Concluem os autores que as peculiaridades do federalismo fiscal brasileiro levam os prefeitos a atrair o maior volume possível de recursos para o seu respectivo município, ainda que, no agregado, gere-se um desequilibro no desempenho fiscal do nível municipal.

Devem-se considerar, quanto a isso, as reformas fiscais ocorridas no Brasil no final dos anos 1990. Para Souza (2005), foram três os principais efeitos dessas reformas no âmbito subnacional: 1) grande limitação à liberdade dos governantes de aplicar recursos próprios, devido à política de ajuste fiscal; 2) estados e municípios tiveram parte de suas receitas vinculadas ao gasto com serviços de saúde e educação fundamental; e 3) as transferências não vinculadas recebidas do governo federal pelos entes subnacionais foram reduzidas. Um subproduto dessa redução da capacidade dos municípios de financiar políticas públicas foi a necessidade de aplicar os recursos remanescentes de forma mais eficiente.

Uma outra questão que se relaciona à capacidade local de financiamento das políticas públicas é a possibilidade de contrair empréstimos. Esta também foi reduzida com as novas regras federais de austeridade fiscal, particularmente a Lei de Responsabilidade Fiscal (LRF), de 2000. O prefeito precisa agora da autorização da respectiva câmara de vereadores e da aprovação do Bacen e do Senado, o que tornou quase impossível a contratação de novos empréstimos.

O objetivo dessas regras foi limitar o crescimento da dívida pública que, para Souza (2005), constitui sério constrangimento tanto para as contas públicas dos diversos níveis de governo quanto para o próprio crescimento econômico do país. Arretche (2003) comunga de semelhante entendimento ao destacar que, com a Constituição de 1988, os governos locais no Brasil, embora ainda dependentes do sistema nacional de transferências fiscais, foram dotados de autonomia para contrair empréstimos, o que levou ao endividamento e à produção de déficits fiscais sistemáticos, contrariando uma expectativa anterior de que a descentralização fiscal produziria responsabilidade fiscal. 
A efetividade das novas regras sobre as contas públicas municipais foi empiricamente demonstrada em estudo efetuado por Sakurai e Filho (2007). Os resultados do estudo indicam que municípios criados mais recentemente possuem pouco ou nenhum endividamento, apresentando, portanto, menores restrições à execução orçamentária. Esse fato, segundo o estudo, favorece o prefeito, elevando a probabilidade de sua efetiva reeleição. Não apenas isso. A probabilidade de permanência no poder é de igual modo favorecida pelo maior volume de gastos realizados durante os três anos que antecedem o ano eleitoral, ao passo que maiores desajustes fiscais em anos de eleição sofrem, de uma maneira geral, avaliação negativa por parte dos eleitores. Os ciclos políticos orçamentários são, portanto, significativos para as pretensões eleitorais dos governos municipais.

\section{Ainda na literatura: a política das políticas públicas}

A literatura identifica relações entre o nível de competitividade eleitoral e a qualidade dos governos locais. Borges (2010), por exemplo, cita evidências empíricas que apontam para uma relação negativa: cenários eleitorais mais competitivos geram incentivos para uma burocracia politicamente menos independente e para estratégias de implementação de políticas públicas menos universalistas. Efeitos dessa natureza, entretanto, seriam próprios de municípios com baixo nível de desenvolvimento econômico. Nas localidades que, ao contrário, ostentam níveis mais elevados de renda e urbanização, o eleitorado demanda bens e serviços públicos de melhor qualidade. Em função disso, a arena eleitoral nos municípios mais ricos e desenvolvidos, quando competitiva e fragmentada, gera maior eficiência na gestão.

Motta e Moreira (2007) corroboram semelhante visão ao entenderem que, nos municípios onde há maior competição eleitoral para cargos no Legislativo ou Executivo, o esforço do prefeito para se reeleger deveria lhe impelir a melhorar a qualidade de sua gestão, levando, assim, a um nível maior de eficiência. Tal resultado depende, contudo, de um sistema de informações que possibilite aos eleitores avaliar a gestão municipal com grau razoável de precisão. A ressalva é que isso não necessariamente ocorre no sistema eleitoral brasileiro, devido ao estado de educação do eleitor. Isso é reforçado por Kerbauy (2001), para quem, nos entes subnacionais onde as elites locais têm maior capacidade de renovação, a exposição à competição política restringe as relações de corte clientelista, de maneira que a maior autonomia decisória decorrente da descentralização contribui para o aperfeiçoamento da ação governamental. Onde, ao contrário, a baixa capacidade de renovação das elites perpetua o clientelismo, a autonomia decisória dos municípios não gera maior eficiência na alocação dos seus recursos em políticas públicas.

Conclui-se, ao final, que, embora a intensidade da disputa política seja um elemento que afete a qualidade da gestão local, ao condicionar o grau de eficiência com que os serviços públicos são prestados, tal disputa revela um caráter por vezes 
antagônico, dado que tanto pode favorecer a melhoria da gestão quanto incentivar a prática do clientelismo.

No que diz respeito às coalizões e à natureza das políticas públicas, Piva (2010) afirma que, por ocasião da constituição das alianças na fase de disputa eleitoral, a formação das coalizões requer a negociação em torno de diretivas programáticas, ainda que mínimas. Os efeitos dessa negociação na gestão municipal se dão com a formulação e implementação da agenda real de políticas, quando a aliança se torna coalizão efetivamente governante.

As coalizões políticas podem, portanto, causar efeitos na qualidade da gestão municipal, na medida em que interferem na própria governabilidade. Ora, falta de cooperação dos partidos com a aprovação dos programas da agenda governista pode gerar paralisia de governo. Em face disso, como enfatiza Amorim Neto (2000), os governantes que, quando eleitos, contam com minoria no Legislativo em função da fragmentação partidária recorrem à formação de coalizões amplas, em que a patronagem do Executivo é uma moeda política importante.

Borges (2010) sugere que, em situações de alta competitividade política, o custo de obter apoio do eleitorado para os partidos/coalizões governistas pode se traduzir numa necessidade de ampliação da oferta de políticas públicas. Se, por um lado, o consequente aumento do gasto público pode representar perdas de performance fiscal, o aumento da competição eleitoral, por outro, tornará os eleitores mais seletivos e exigentes, levando à melhoria na provisão de bens e serviços públicos.

A literatura apresenta evidências ainda de que o alinhamento partidário com o presidente da República ou com o governador tende a afetar positivamente as chances de os prefeitos manterem-se no poder (vide, por exemplo, Sakurai e Filho, 2007; Veiga, Santos e Neves, 2011). Uma das explicações seria que os investimentos e gastos dos governos estadual e federal favoreceriam a gestão do prefeito, por beneficiar a população do município. Uma vez que se trata de investimentos públicos não contabilizados no orçamento do município, tendem a ser avaliados como benefícios que chegam sem custos adicionais para o seu eleitorado.

A influência do alinhamento partidário vertical na governabilidade pode igualmente se observar a partir do sistema de transferências de recursos entre União, estados e municípios, o que pode significar uma maior probabilidade de permanência no poder em face da possibilidade de maior execução financeira. Há, ademais, formas de favorecimento intergovernamental que não necessariamente envolvem questões orçamentárias, como o apoio dos governantes estadual e federal nas campanhas eleitorais do município que, de alguma maneira, representa impacto sobre a gestão do prefeito.

Os investimentos, recursos e apoio político viabilizados em decorrência do alinhamento privilegiam de forma diferenciada os prefeitos, a depender do interesse político do governador ou do presidente, que se representa pelo desempenho nas urnas 
dos candidatos que apoiam no município. Tal desempenho, segundo Motta e Moreira (2007), pode ser mensurado em termos da diferença de votos entre o candidato ao final eleito e o segundo candidato mais votado.

Finalmente, em termos político-partidários, Gouveia (2009) reconhece que há limites na caracterização dos partidos brasileiros como absolutamente antagônicos no binômio esquerda/direita. Em face disso, a bandeira ideológica dos partidos no poder pode não refletir o que os governos locais propõem de fato para a questão social. Carreirão (2006), ao contrário, entende que o posicionamento ideológico do partido repercute na opinião pública e no eleitorado de maneira a limitar as decisões da coligação no campo das políticas públicas a padrões ideológicos minimamente esperados, sob pena de incorrer em custos político-eleitorais futuros.

A despeito do fato de os impactos da ideologia no federalismo brasileiro ainda não serem suficientemente conhecidos e estudados, Borges (2010) atesta que a onda crescente de políticas federais de transferência de renda implementadas por partidos de esquerda tem paulatinamente reduzido o controle outrora exercido pelos governos estaduais sobre a arena eleitoral dos municípios, gerando incentivos diferenciados à gestão local do gasto social.

\section{Aspectos metodológicos}

Tendo por base a literatura acima visitada, partimos inicialmente para uma pesquisa descritivo-explicativa, que teve como objeto a quase totalidade do universo das gestões municipais brasileiras iniciadas em 2005 e finalizadas em 2008. Os dados são quantitativos e foram coletados através de fontes secundárias, sendo elas o Tribunal Superior Eleitoral (TSE), a Federação das Indústrias do Estado do Rio de Janeiro (Firjan), o Instituto Brasileiro de Geografia e Estatística (IBGE) e a Caixa Econômica Federal (CEF), através do Sistema de Informações Socioeconômicas dos Municípios Brasileiros (Simbrasil).

Foi utilizado, como variável dependente, o Índice Firjan de Gestão Fiscal (IFGF) para os anos de 2007 e 2008. Esse índice foi utilizado como indicador de equilíbrio fiscal das gestões municipais nos dois últimos anos das gestões analisadas, ou seja, esse é o indicador de bom governo utilizado neste artigo ${ }^{1}$.

As variáveis explicativas foram divididas em dois grupos: política e gestão. No primeiro estão contidas: 1) proporção de abstenção eleitoral (2004); 2) distância proporcional entre o candidato eleito e o segundo mais votado $(2004)$; 3) número efetivo de partido nas câmaras de vereadores (2004); 4) tamanho da coligação do prefeito eleito

\footnotetext{
${ }^{1}$ O IFGF é produzido anualmente pela Firjan, e é composto por cinco indicadores: Receita Própria, Gastos com Pessoal, Investimentos, Liquidez e Custo da Dívida. Já o IFDM é produzido pela mesma Federação, e é composto por um grande número de variáveis, que buscam capturar a situação de três áreas distintas: 1) emprego e renda, 2) educação e 3) saúde. Esses índices são produzidos a partir de dados oficiais e podem ser acessados em: <http://www.firjan.org.br/>.
} 
(2004); e 5) proporção de partidos de esquerda que compunham a coligação do prefeito eleito (2004). Com essas variáveis se deseja verificar em que medida a baixa participação eleitoral, a competição política, bem como as alianças eleitorais influenciam na variabilidade do equilíbrio fiscal da gestão municipal. Maior abstenção eleitoral pode significar menos constrangimento ao comportamento do gestor, o que, no limite, pode gerar menos responsabilidade em suas ações. Já os indicadores de competição e coligação relacionam-se com problemas de governabilidade. Quanto maior o número efetivo de partidos, por exemplo, maior seria a quantidade de atores a negociar, o que poderia onerar o custo da governabilidade. Coligações com um grande número de partidos, da mesma forma, geram dificuldades para os gestores acomodarem os interesses diante dos recursos disponíveis, o que pode significar menos racionalidade no gasto, e, portanto, maior desequilíbrio.

No grupo de variáveis de gestão, foi utilizada a proporção de funcionários com formação superior nas prefeituras (2004) e o Índice de Instrumentos de Planejamento (2001). Esse índice é a soma simples da existência nos municípios, no ano de 2001 , de leis que regulamentam algumas atividades, sendo elas: o Plano Diretor, a Lei do Perímetro Urbano e a Lei de Zoneamento ou Equivalente $(0=$ inexistência; $1=$ existência). Espera-se que uma burocracia com maior know-how signifique maior capacidade administrativa e, assim, maior eficiência. Já os instrumentos de planejamento podem significar maior controle das ações dos gestores, ou seja, mais institucionalização, portanto, mais constrangimento a ações irresponsáveis.

Com as variáveis acima foram aplicadas técnicas estatísticas descritivas e inferenciais, o que possibilitou testar que variáveis políticas realmente importam na qualidade dos governos municipais.

\section{Padrões de gestão fiscal nos municípios brasileiros}

O equilíbrio fiscal das contas públicas tem sido a tônica do debate quando se discute a capacidade dos gestores públicos em implementar políticas que atendam a contento às demandas existentes. Para tanto é imprescindível desenvolver mecanismos eficientes de arrecadação, diminuir custos e aumentar investimentos, os quais venham a produzir resultados efetivos.

O Índice Firjan de Gestão Fiscal (IFGF) propicia análises comparativas importantes sobre a saúde fiscal dos municípios brasileiros, inclusive desagregados por componentes. Esse índice varia entre 0 e 1, sendo que, quanto maior o número, melhor a gestão fiscal do município em tela. Pouco mais de cem municípios no país possuem nota próxima da máxima. Na média, conforme pode ser visto na Tabela 1, os municípios brasileiros apresentam um índice de 0,536, ou seja, bem distante daquilo que seria o ideal. 
Na mesma tabela ainda é possível verificar a capacidade dos municípios em gerar receitas próprias. Em média, os municípios brasileiros atingem apenas $25 \%$ da nota máxima desse indicador, o que sugere debilidades importantes na capacidade de incrementar o caixa por meio de esforços próprios:

Tabela 1

IFGF e componentes internos (2010)

\begin{tabular}{|l|c|c|c|c|c|c|c|}
\hline & & & \multicolumn{5}{|c|}{ Componentes do IFGF } \\
\hline $\begin{array}{l}\text { Unidade } \\
\text { geográfica }\end{array}$ & $\mathbf{N}$ & IFGF & $\begin{array}{c}\text { Receita } \\
\text { própria }\end{array}$ & $\begin{array}{c}\text { Gastos com } \\
\text { pessoal }\end{array}$ & Investimentos & Liquidez & $\begin{array}{c}\text { Custo } \\
\text { da } \\
\text { dívida }\end{array}$ \\
\hline Brasil & 5.287 & 0,536 & 0,252 & 0,577 & 0,618 & 0,576 & 0,804 \\
\hline Norte & 391 & 0,533 & 0,196 & 0,561 & 0,654 & 0,581 & 0,848 \\
\hline Nordeste & 1.668 & 0,438 & 0,160 & 0,494 & 0,527 & 0,413 & 0,797 \\
\hline Sudeste & 1.612 & 0,568 & 0,311 & 0,600 & 0,660 & 0,588 & 0,822 \\
\hline Sul & 1.174 & 0,617 & 0,300 & 0,667 & 0,691 & 0,745 & 0,758 \\
\hline $\begin{array}{l}\text { Centro- } \\
\text { Oeste }\end{array}$ & 442 & 0,571 & 0,299 & 0,588 & 0,583 & 0,692 & 0,850 \\
\hline
\end{tabular}

Fonte: Elaboração própria com base em dados da Firjan.

Os dados divulgados pela Firjan permitem acompanhar a evolução do IFGF por um período de cinco anos (2006-2010). Apesar de esse ser um tempo curto, possibilita verificar alguns padrões. Primeiro, ressalte-se que a evolução do índice, na média, não se apresenta linear. Ao que parece, há momentos de avanços e de recrudescimento. Há um ponto de inflexão que pode ser destacado na Tabela 2. Verifica-se que de 2008 para 2009 houve uma queda dos índices médios para todos os recortes geográficos. De todos os municípios passíveis de comparação entre esses anos, 3.638 (74\%) apresentaram variação negativa, 172 (4\%) se mantiveram com o mesmo índice e apenas 1.101 (22\%) conseguiram evoluir. Dentre os componentes que contribuíram negativamente para esse quadro, sobressai o gasto com pessoal $(-12,90 \%)$, os investimentos $(-15,53 \%)$ e a liquidez $(-4,17 \%)$. Destaque-se que esse momento marca a passagem de um mandato para outro, e essa queda pode estar associada a gastos excessivos no ano eleitoral ou mesmo à mudança de equipe de governo. Importante lembrar dos eventos relativos à crise financeira internacional de 2008, que impactaram negativamente em alguns setores da economia brasileira, principalmente no primeiro semestre do ano de 2009. 
Tabela 2

Evolução do IFGF (2006-2010)

\begin{tabular}{|l|c|c|c|c|c|c|c|}
\hline & \multicolumn{7}{|c|}{ Anos } \\
\hline Unidade geográfica & \multicolumn{7}{|c|}{ 2006-2010 } \\
\hline & 2006 & 2007 & 2008 & 2009 & 2010 & $2006-2008$ & $2009-2010$ \\
\hline Brasil & 0,530 & 0,529 & 0,580 & 0,503 & 0,536 & 0,546 & 0,519 \\
\hline Norte & 0,547 & 0,523 & 0,556 & 0,492 & 0,533 & 0,542 & 0,512 \\
\hline Nordeste & 0,469 & 0,458 & 0,504 & 0,424 & 0,438 & 0,477 & 0,431 \\
\hline Sudeste & 0,545 & 0,542 & 0,606 & 0,522 & 0,568 & 0,564 & 0,545 \\
\hline Sul & 0,590 & 0,605 & 0,641 & 0,587 & 0,617 & 0,612 & 0,602 \\
\hline Centro-Oeste & 0,533 & 0,549 & 0,605 & 0,525 & 0,571 & 0,562 & 0,548 \\
\hline
\end{tabular}

Fonte: Elaboração própria com base em dados da Firjan.

As notas do IFGF podem ser categorizadas e agregadas em grupos de municípios. Isso possibilita visualizar onde se localiza a maioria dos municípios. A gestão daqueles que obtêm nota inferior a 0,4 é considerada crítica. Gestão em dificuldades são aquelas que possuem nota entre 0,4 e 0,6. Municípios com boa gestão são aqueles com nota entre 0,6 e 0,8 . E aqueles com nota superior a 0,8 são considerados como gestão de excelência.

A Tabela 3 permite visualizar as médias nacional e por regiões dos municípios distribuídos por categorias do IFGF. É possível verificar consequentemente a qualidade das gestões. Na média brasileira, verifica-se que, de cada dez municípios, pelo menos seis possuem gestão considerada crítica ou em dificuldade. Esse quadro se apresenta mais grave na região Nordeste, onde $88 \%$ dos municípios apresentaram gestão crítica ou com dificuldades para equilibrar suas contas:

Tabela 3

Categorias do IFGF - 2010

\begin{tabular}{|c|c|c|c|c|c|c|c|c|c|}
\hline & \multicolumn{7}{|c|}{ Categorias do IFGF } & \% \\
\hline $\begin{array}{c}\text { Unidade } \\
\text { geográfica }\end{array}$ & \multicolumn{2}{|c|}{$\begin{array}{c}\text { Gestão crítica } \\
\text { (D) }\end{array}$} & \multicolumn{2}{|c|}{$\begin{array}{c}\text { Gestão em } \\
\text { dificuldade } \\
\text { (C) }\end{array}$} & \multicolumn{2}{c|}{$\begin{array}{c}\text { Boa gestão } \\
\text { (B) }\end{array}$} & \multicolumn{2}{c|}{$\begin{array}{c}\text { Gestão de } \\
\text { excelência } \\
\text { (A) }\end{array}$} & Total \\
\hline Brasil & 1.009 & 20,09 & 2.225 & 44,30 & 1.714 & 34,12 & 75 & 1,49 & N \\
\hline Norte & 74 & 19,68 & 173 & 46,01 & 123 & 32,71 & 6 & 1,60 & 376 \\
\hline Nordeste & 635 & 39,86 & 772 & 48,46 & 181 & 11,36 & 5 & 0,31 & 1.593 \\
\hline Sudeste & 186 & 12,22 & 688 & 45,20 & 612 & 40,21 & 36 & 2,37 & 1.522 \\
\hline Sul & 68 & 6,10 & 396 & 35,55 & 627 & 56,28 & 23 & 2,06 & 1.114 \\
\hline $\begin{array}{c}\text { Centro- } \\
\text { Oeste }\end{array}$ & 46 & 11,00 & 196 & 46,89 & 171 & 40,91 & 5 & 1,20 & 418 \\
\hline
\end{tabular}

Fonte: Elaboração própria com base em dados da Firjan. 
Verifica-se que aproximadamente $64 \%$ dos municípios brasileiros possuem gestão crítica ou em dificuldade (Tabela 4), o que denota uma enorme fragilidade em seu equilíbrio fiscal, e no limite pode significar represamento de demandas:

Tabela 4

Categorias do IFGF - 2010

\begin{tabular}{|l|c|c|c|}
\hline \multirow{2}{*}{ Categoria } & \multicolumn{3}{|c|}{ Brasil } \\
\cline { 2 - 4 } & $\mathbf{N}$ & \% & Acumulado \\
\hline Gestão crítica & 1.009 & 20,09 & 20,09 \\
\hline Gestão em dificuldade & 2.225 & 44,30 & 64,38 \\
\hline Boa gestão & 1.714 & 34,12 & 98,51 \\
\hline Gestão de excelência & 75 & 1,49 & 100,00 \\
\hline & 5.023 & 100,00 & \\
\hline
\end{tabular}

Fonte: Elaboração própria com base em dados da Firjan.

$\mathrm{Na}$ Tabela 5 é possível verificar as oscilações da média do IFGF dos municípios por ano. Percebe-se mais uma vez a concentração dos municípios nas categorias gestão crítica e gestão com dificuldade.

$\mathrm{Na}$ Tabela 2 viu-se, analisando apenas os índices, que no ano de 2008 houve uma piora generalizada dos índices dos municípios. Nesse ano, como pode ser visto na Tabela 5, havia 117 municípios classificados como gestão de excelência e no ano seguinte esse número diminuiu para 49. Ressalte-se que dos 117, a Firjan disponibilizou dados para apenas 77 em 2009. Destes, 75\% se localizam nos estados de São Paulo (33) e Rio Grande do Sul (25). Isso sugere que municípios de estados detentores de boa posição no índice também sofrem influência no momento eleitoral ou de mudança de gestão.

Tabela 5

Evolução das categorias do IFGF (2006-2010) - BRASIL

\begin{tabular}{|c|c|c|c|c|c|c|c|c|c|}
\hline \multirow{2}{*}{ Anos } & \multicolumn{2}{|c|}{$\begin{array}{c}\text { Gestão } \\
\text { crítica }\end{array}$} & \multicolumn{2}{c|}{ Gestão em dificuldade } & \multicolumn{2}{c|}{$\begin{array}{c}\text { Boa } \\
\text { gestão }\end{array}$} & \multicolumn{2}{c|}{$\begin{array}{c}\text { Gestão de } \\
\text { excelência }\end{array}$} & \multirow{2}{*}{ Total } \\
\hline & $\mathbf{N}$ & $\%$ & $\mathbf{N}$ & \% & $\mathbf{N}$ & $\%$ & $\mathbf{N}$ & $\%$ & \\
\hline 2006 & 1.061 & 20,53 & 2.450 & 47,4 & 1.597 & 30,9 & 61 & 1,18 & 5.169 \\
\hline 2007 & 1.094 & 21,58 & 2.334 & 46,04 & 1.572 & 31,01 & 70 & 1,38 & 5.070 \\
\hline 2008 & 590 & 12,19 & 1.965 & 40,61 & 2.167 & 44,78 & 117 & 2,42 & 4.839 \\
\hline 2009 & 1.322 & 25,95 & 2.423 & 47,57 & 1.300 & 25,52 & 49 & 0,96 & 5.094 \\
\hline 2010 & 1.009 & 20,09 & 2.225 & 44,3 & 1.714 & 34,12 & 75 & 1,49 & 5.023 \\
\hline
\end{tabular}

Fonte: Elaboração própria com base em dados da Firjan. 


\section{Fatores políticos que condicionam bons governos}

$\mathrm{Na}$ busca de evidências empíricas que permitissem testar se variáveis políticas afetam o equilíbrio fiscal dos municípios, neste artigo medido pelo IFGF, foram elaborados dois modelos de regressão linear múltipla, sendo esta escolhida pelo tipo de variável dependente utilizada, no caso, uma ordinal.

O IFGF foi testado para o ano de 2007 e 2008, os dois últimos anos da gestão municipal analisada, qual seja, 2005/2008. Como visto anteriormente, esse índice não possui linearidade ao longo do tempo, sendo sensível a período eleitoral ou mesmo a mudança na gestão. A análise de anos posteriores, portanto, noutra gestão, poderia levar ao risco de avaliar um índice pouco influenciado pela gestão anterior, que é o foco do artigo.

Inseriram-se nos modelos cinco variáveis políticas, duas de gestão e três de controle, sendo estas últimas a renda per capita municipal para o ano de 2004, o Índice de Desenvolvimento Humano Municipal e o log da população, ambos para o ano de 2000.

Das cinco variáveis políticas, quatro no primeiro modelo e três no segundo apresentaram significância estatística para explicar a variação no IFGF, conforme pode ser visto na Tabela 6.

A primeira variável refere-se à proporção de eleitores que se abstiveram de votar no pleito eleitoral de 2004. Sabe-se que eleições podem operar como mecanismos de controle, ou seja, de accountability, no caso vertical. Governantes podem ser punidos e premiados conforme seu desempenho, isso num ambiente hipotético de informação perfeita. Eleitores que não se utilizam desse instrumento para controlar seus governantes podem, sob esse prisma, diminuir o constrangimento provocado pelo processo eleitoral, produzindo, dessa forma, governos menos comprometidos com a gestão, portanto, menos responsivos. No primeiro modelo, é possível verificar essa relação. Sugere-se que nos municípios com maior abstenção eleitoral, ou seja, eleitores menos participativos no processo, há maior desequilíbrio fiscal, com uma significância estatística a $1 \%$ para o ano de 2007. No entanto, o mesmo fenômeno não se manifestou para o ano de 2008, pois a variável proporção de eleitores que não votaram na eleição de 2004 não apresentou significância estatística no modelo 2 , embora continue com o sinal negativo esperado.

Sugere-se que aspectos da competição eleitoral podem afetar a qualidade da gestão. Duas variáveis foram inseridas para testar essa premissa. A primeira se refere ao monopólio eleitoral do prefeito. Parte-se do pressuposto de que aqueles eleitos com uma grande margem de votos tenderiam, por sua condição privilegiada, a colocar em segundo plano os interesses de seus representados e passar a priorizar uma agenda de caráter particularista $^{2}$. No entanto, essa variável não apresentou qualquer significância

\footnotetext{
${ }^{2}$ Vale ressaltar que, nas eleições de 2004, em nada menos que 555 municípios essa diferença foi superior a $100 \%$.
} 
estatística para explicar a variação do IFGF. Ou seja, o volume de voto atingido junto ao eleitorado não produz efeitos importantes na variação da qualidade da gestão. No entanto, a segunda variável de competição testada, número de partidos efetivos, apresentou sim significância estatística. Um maior número de partidos na arena legislativa aumenta os custos de transação do Executivo municipal, podendo, inclusive, gerar problemas de governabilidade ${ }^{3}$. Isso faz com que o prefeito se utilize dos recursos disponíveis da prefeitura para ampliar sua base de apoio, mesmo que isso signifique desequilíbrio nas contas municipais, o que é corroborado pelo teste da Tabela 6 .

Além do número efetivo de partidos, testou-se também o número de partidos que fizeram parte da coligação que elegeu o prefeito. A hipótese sugerida é de que um número elevado de partidos que dão suporte no processo eleitoral pode significar um número maior de partidos na base do governo, ampliando o número de atores a fazer parte da gestão, que poderia significar mais gastos, portanto, possibilidade de desequilíbrio nas contas. Os testes apontam uma relação significativa, mas no sentido inverso, o que não corrobora a hipótese levantada neste artigo.

A última variável política testada diz respeito à proporção de partidos de esquerda que fizeram parte da coligação que elegeu o prefeito. É uma variável que busca aferir a influência do espectro ideológico ${ }^{4}$. Da mesma forma que a variável anterior, pressupõe-se que parte dos partidos da coligação passe a constituir a coalizão governamental, se a maioria dos partidos da coligação é de esquerda, os da coalizão também tenderão a ser. Pergunta-se então: a maioria de partidos de esquerda gera um efeito positivo na saúde fiscal dos municípios? Os modelos sugerem que sim, ou seja, quanto mais partidos de esquerda na coligação, maior equilíbrio fiscal, segundo os dados aqui trabalhados.

O segundo grupo de variáveis utilizado na regressão buscou testar aspectos endógenos à própria gestão, as quais apresentaram significância e influência positiva. A primeira dela diz respeito ao Índice de Instrumentos de Planejamento. Essa variável é estruturada levando em consideração a existência ou não de alguns dispositivos normativos que regulem o comportamento do gestor. O pressuposto é de que, quanto mais dispositivos desse tipo, mais constrangimento para o comportamento do prefeito, diminuindo assim a margem para ações particularistas.

Já a variável proporção de funcionários com formação superior está diretamente ligada ao know-how administrativo que detém o prefeito. Espera-se que, quanto mais expertise burocrática, mais planejamento, o que gera maior eficiência e, por conseguinte, maior equilíbrio fiscal, o que de fato é corroborado pelos modelos da Tabela 6:

\footnotetext{
3 Para a Nova Economia Institucional, os custos de transação são os custos de garantir que um contrato será cumprido. A expressão está associada a conceitos como racionalidade limitada, incerteza e oportunismo (Williamson, 2002).

${ }^{4} \mathrm{O}$ critério de classificação dos partidos quanto ao espectro ideológico está contido em Krause et al. (2010, p. 380-382).
} 
Tabela 6

Variáveis políticas e o IFGF - Regressão linear múltipla - 2007 e 2008

\begin{tabular}{|c|c|c|c|c|}
\hline \multirow[b]{3}{*}{ Covariáveis } & \multicolumn{2}{|c|}{ Modelo 1} & \multicolumn{2}{|c|}{ Modelo 2} \\
\hline & \multicolumn{2}{|c|}{ IFGF - 2007} & \multicolumn{2}{|c|}{ IFGF - 2008} \\
\hline & Coef. & $\begin{array}{c}\text { Erro- } \\
\text { padrão } \\
\text { Robusto }\end{array}$ & Coef. & $\begin{array}{c}\text { Erro- } \\
\text { padrão } \\
\text { Robusto }\end{array}$ \\
\hline Proporção de abstenção eleitoral (2004) & $-0,001 * *$ & 0,000 & $-0,001$ & 0,000 \\
\hline $\begin{array}{l}\text { Distância proporcional entre o prefeito eleito e } \\
\text { o segundo mais votado ( } 2004)\end{array}$ & $-0,000$ & 0,000 & $-0,000$ & 0,000 \\
\hline Número de partidos efetivos (2004) & $-0,005 * *$ & 0,001 & $-0,004 * *$ & 0,001 \\
\hline Número de partidos na coligação do prefeito eleito (2004) & $0,003 * *$ & 0,001 & $0,002 * *$ & 0,001 \\
\hline $\begin{array}{l}\text { Proporção de partidos de esquerda na } \\
\text { coligação do prefeito eleito ( } 2004)\end{array}$ & $0,000 * *$ & 0,000 & $0,000 *$ & 0,000 \\
\hline Índice de instrumentos de planejamento (2001) & $0,013 * *$ & 0,002 & $0,011^{* *}$ & 0,002 \\
\hline $\begin{array}{l}\text { Proporção de funcionários da administração } \\
\text { direta com formação superior (2004) }\end{array}$ & $0,001 * *$ & 0,000 & $0,001 * *$ & 0,000 \\
\hline Renda per capita municipal (2004) & $0,000 * *$ & 0,000 & $0,000 * *$ & 0,000 \\
\hline IDH (2000) & $0,539 * *$ & 0,032 & $0,624 * *$ & 0,031 \\
\hline Log da população (2000) & 0,001 & 0,005 & $-0,007$ & 0,005 \\
\hline Constante & $0,120 * *$ & 0,025 & 0,151 & 0,026 \\
\hline $\mathrm{R}^{2}$ & \multicolumn{2}{|c|}{0,205} & \multicolumn{2}{|c|}{0,213} \\
\hline $\mathrm{N}$ & \multicolumn{2}{|c|}{4.889} & \multicolumn{2}{|c|}{4.681} \\
\hline
\end{tabular}

Fonte: Elaboração própria com base em dados do TSE, Firjan, IBGE e SimbrasiL/CEF.

Significância: $* p<, 05, * * p<, 001$.

Com vista a detectar problemas de multicolinearidade, heterocedasticidade e autocorrelação, os quais poderiam violar os pressupostos dos modelos 1 e 2 (Tabela 6), e tornar as estimativas imprecisas, procedeu-se aos testes Variance Inflation Factor (VIF), Breusch-Pagan, White, e Durbin Watson. Os resultados do VIF sugerem que não há problemas de multicolinearidade, cujos valores são 1,43 e 1,44 para 2007 e 2008 respectivamente. Para que existisse o problema, esse valor teria que ser superior a 10,00. Os detalhes podem ser observados na Tabela 7 do Apêndice. Por outro lado, os modelos apresentaram problemas de heterocedasticidade, uma vez que a partir dos testes Breusch-Pagan e White a hipótese nula de homocedasticidade foi rejeitada a significância de $1 \%$ em ambos os testes. Dentre as formas existentes para corrigir o problema, optou-se pela correção Robusta de White, que é amplamente utilizada, a qual ajusta os erros-padrão a partir da heterocedasticidade do próprio modelo. Já em relação aos problemas envolvendo autocorrelação, que também poderia produzir estimativas imprecisas, a partir do teste de Durbin Watson verificou-se sua inexistência, uma vez que o valor obtido foi de 1,83. Para que houvesse autocorrelação negativa ou positiva, esse número deveria ser inferior a 1,5 ou superior a 2,5 respectivamente. Sugere-se, portanto, que as variáveis dos modelos apresentados possuem validade e explicam de fato, segundo os $\mathrm{R}^{2}$, pelo menos $20 \%$ da variação do equilíbrio fiscal das gestões municipais, o que na prática significa melhoria da qualidade dos governos. 


\section{Considerações finais}

O modelo federativo do Brasil pós-1988 estabeleceu uma agenda de descentralização das políticas públicas, e, nos casos das políticas de educação e saúde, por exemplo, os governos municipais passaram a ter um papel de extrema relevância na oferta dos serviços. Contudo, a característica de desigualdade socioeconômica prevalecente no território coloca inúmeras indagações teóricas importantes, especialmente sobre a questão dos bons governos, entendidos a partir do prisma do equilíbrio fiscal e da capacidade de atender adequadamente às demandas da população local.

Neste artigo, analisamos os principais aspectos levantados pela literatura nacional quanto ao papel e ao desempenho dos governos locais no país e emerge desta uma série de fatores de ordem institucional e não institucional com importância na qualidade das gestões locais. São fatores que exercem graus variados de influência na capacidade gestora dos governos municipais e, por conseguinte, na sua eficiência para atendimento das demandas de políticas públicas da população.

Sem sombra de dúvidas, as questões gêmeas de política e bons governos têm se colocado entre as mais controversas nos estudos sobre a qualidade da gestão municipal, e tomamos aqui a variável do equilíbrio fiscal como condição necessária para garantir a governança dos gestores públicos, o que lhes permitiria executar uma agenda concatenada com as demandas da sociedade.

Sob esse cenário, a situação dos municípios brasileiros não é favorável, isso tomando como parâmetro o IFGF. A maior parte dos municípios enquadra-se como gestões críticas ou em dificuldades. Esse quadro é agravado ainda mais nos municípios das regiões e estados mais pobres do Brasil.

Além disso, fatores políticos são de fato relevantes para explicar tal fenômeno, a exemplo da abstenção eleitoral e o número efetivo de partidos na arena legislativa, que onera o custo de transação do Executivo municipal. Fatores endógenos à gestão também são relevantes para explicar a variação do fenômeno, em especial os dispositivos normativos que constranjam o comportamento do gestor, como também a expertise burocrática.

Clóvis Alberto Vieira de Melo - Unidade Acadêmica de Ciências Sociais, Centro de Humanidades, Universidade Federal de Campina Grande. Doutor em Ciência Política (UFPE). E-mail: <clovis.melo@ufcg.edu.br>.

Saulo Santos de Souza - Mestrado Profissional em Políticas Públicas, Universidade Federal de Pernambuco. Curso de Relações Internacionais, Faculdade Asces. Doutor em Ciência Política (UFPE). Ph.D. em Economia (University of Cambridge, UK). E-mail: <souzasaulo@hotmail.com>.

Washington Luís de Sousa Bonfim - Departamento de Ciências Sociais, Centro de Ciências Humanas e Letras, Universidade Federal do Piauí. Doutor em Ciência Política (Iuperj). E-mail: $<$ washbonfim@gmail.com>. 


\section{Referências bibliográficas}

AMORIm Neto, O. "Gabinetes presidenciais, ciclos eleitorais e disciplina legislativa no Brasil". Dados, vol. 43, n³, p. 479-519, 2000.

ANDREWS, M. "Good government means different things in different countries". Governance: An International Journal of Policy, Administration and Institutions, vol. 23, n 1, p. 7-35, 2010.

ARretche, M. "Políticas sociais no Brasil: descentralização em um Estado federativo". Revista Brasileira de Ciências Sociais, vol. 14, n 40, p. 111-141, 1999.

. "Financiamento federal e gestão local de políticas sociais: o difícil equilíbrio entre regulação, responsabilidade e autonomia". Ciência e Saúde Coletiva, vol. 8, n 2, p. 331-345, 2003.

Borges, A. "Federalismo, dinâmica eleitoral e políticas públicas no Brasil: uma tipologia e algumas hipóteses". Sociologias, ano 12, n²4, p. 120-157, 2010.

CARreirão, Y. S. "Ideologia e partidos políticos: um estudo sobre coligações em Santa Catarina". Opinião Pública, vol. 12, nº 1, p. 136-163, 2006.

COSTA, J.; CUNHA, M.; ARAújo, R. "Federalismo cooperativo brasileiro: implicações na gestão da educação municipal". Jornal de Políticas Educacionais, nº 8, p. 14-23, 2010.

GouveIA, A. B. "Avaliação da política educacional municipal: em busca de indicadores de efetividade nos âmbitos do acesso, gestão e financiamento". Ensaio: Avaliação de Políticas Públicas, Rio de Janeiro, vol. 17, nº 64, p. 449-476, 2009.

Kerbauy, M. T. "Federalismo, descentralização e democracia". Estudos de Sociologia, vol. 2, nº 10, p. $51-61,2001$.

KRAUSE, S. et al. (orgs.). Coligações partidárias na nova democracia brasileira: perfis e tendências. Rio de Janeiro: Konrad-Adenuer-Stiftung; São Paulo: Editora da Unesp, 2010.

Mendes, M.; RochA, C. O que reelege um prefeito?. Consultoria Legislativa do Senado Federal: textos para discussão, $n^{\circ}$ 7, 2004.

MotTA, R.; MoreirA, A. Eficiência na gestão municipal no Brasil. Texto para discussão n 1301 . Ipea, 2007.

PIVA, O. "Presidencialismo de coalizão: uma introdução ao tema". Cultura e Fé, vol. 33, no 130, p. 363-373, 2010.

SAKURAI, S.; FILHO, N. "Política fiscal e reeleição nos municípios brasileiros: uma análise via dados em painel para o período 1988-2000". In: Anais do XXXV Encontro Nacional de Economia - Anpec, 2007.

SouzA, C. "Reinventando o poder local: limites e possibilidades do federalismo e da descentralização". São Paulo em Perspectiva, vol. 10, nº 3, p. 103-112, 1996.

. "Federalismo, desenho constitucional e instituições federativas no Brasil pós-1988".

Revista de Sociologia e Política, n²4, p. 105-121, 2005.

TótorA, S.; ChAIA, V. "Conselhos municipais: descentralização, participação e limites institucionais". Cadernos Metrópole, n 8, p. 59-86, 2002.

VeigA, L.; SAntos, S.; NeVes, D. "Como a avaliação do governo local, a imagem dos candidatos e a configuração da disputa influenciam na reeleição do prefeito: evidências de oito capitais no Brasil, 
2008". In: IV Congresso Latino Americano de Opinião Pública da WAPOR. Belo Horizonte, 4-6 maio 2011.

WILLIAMSON, O. "The theory of the firm as governance structure: from choice to contract". Journal of Economic Perspectives, vol. 16, n³, p. 171-195, 2002.

\section{Apêndice}

Tabela 7 - Teste de Multicolinearidade - Variável Dependente: IFGF - 2007/2008 (Variance Inflation Factor - VIF)

\begin{tabular}{|l|c|c|c|c|}
\hline Variáveis Independentes & \multicolumn{1}{c|}{ IFGF-2007 } & \multicolumn{2}{c|}{ IFGF-2008 } \\
\hline & VIF & $\mathbf{1 / V I F}$ & VIF & $\mathbf{1} /$ VIF \\
\hline Proporção de abstenção eleitoral - 2004 & 1,64 & 0,611 & 1,64 & 0,611 \\
\hline $\begin{array}{l}\text { Distância proporcional entre o prefeito eleito e o segundo } \\
\text { mais votado - 2004 }\end{array}$ & 1,01 & 0,994 & 1,01 & 0,994 \\
\hline Número de partidos efetivos - 2004 & 1,32 & 0,759 & 1,33 & 0,752 \\
\hline Número de partidos na coligação do prefeito eleito - 2004 & 1,35 & 0,743 & 1,35 & 0,741 \\
\hline $\begin{array}{l}\text { Proporção de partidos de esquerda na coligação do } \\
\text { prefeito eleito - 2004 }\end{array}$ & 1,01 & 0,991 & 1,01 & 0,991 \\
\hline Índice de instrumentos de planejamento - 2001 & 1,56 & 0,642 & 1,57 & 0,635 \\
\hline $\begin{array}{l}\text { Proporção de funcionários da administração direta com } \\
\text { formação superior - 2004 }\end{array}$ & 1,21 & 0,825 & 1,22 & 0,821 \\
\hline Renda Per Capita Municipal - 2004 & 1,29 & 0,773 & 1,31 & 0,761 \\
\hline Índice de Desenvolvimento Humano Municipal - 2000 & 1,81 & 0,553 & 1,83 & 0,547 \\
\hline Log da População - 2000 & 2,08 & 0,480 & 2,11 & 0,473 \\
\hline Média VIF & & & & \\
\hline
\end{tabular}

Fonte: Elaboração própria com base em dados do TSE, Firjan, IBGE e Simbrasil/CEF.

\section{Resumo}

Federalismo e bons governos: uma análise política da gestão fiscal dos municípios

Passados 25 anos da promulgação da Constituição de 1988, a qual inaugurou um novo patamar das relações entre os entes federativos no Brasil, pergunta-se: esse novo desenho institucional foi capaz de gerar bons governos no âmbito municipal? Consideram-se bons governos as gestões que possuem equilíbrio fiscal em suas contas. Analisou-se o equilíbrio fiscal para a quase totalidade dos municípios brasileiros no ano de 2010, utilizando-se para isso o Índice Firjan de Gestão Fiscal (IFGF), produzido pela Federação das Indústrias do Estado do Rio de Janeiro (Firjan). Os dados sugerem um país em que seus municípios possuem resultados fiscais bastante díspares. A partir de uma escala que varia de 0 a 1, verificaram-se municípios com gestão crítica, com índices próximos de 0 , e aqueles com uma gestão considerada excelente, com índices próximos a 1 . Em média, os municípios brasileiros apresentaram taxa que superam pouco mais da metade desse índice. Para explicar essa variabilidade testaram-se variáveis de gestão e políticas, as quais foram coletadas junto ao Tribunal Superior Eleitoral (TSE) e ao Instituto Brasileiro de Geografia e Estatística (IBGE). Verificou-se que o nível de equilíbrio fiscal está condicionado aos níveis de competição política e participação eleitoral, como também aos níveis de formação dos funcionários da administração direta dos municípios analisados.

Palavras-chave: bons governos; federalismo; equilíbrio fiscal 


\begin{abstract}
Federalism and good governments: a political analysis of the municipalities' fiscal management
\end{abstract}

Twenty-five years after the promulgation of the 1988 Constitution, which itself initiated a new pattern of intergovernmental relations in Brazil, a question can be asked: was this new institutional design able to foster good governments at the level of the municipalities? We consider as good governments the administrations presenting fiscal balance in their public accounts. We analyze the fiscal balance for about all Brazilian municipalities (2010) by means of the Firjan Index of Fiscal Management (IFGF) released by the Federation of Industries of the State of Rio de Janeiro (Firjan). These data suggest that the municipalities yield considerably different fiscal results. Given a 0 to 1 scale, we detected municipalities with critically low fiscal management, with an index close to 0 , and municipalities with excellent fiscal management, with an index close to 1 . In average, the Brazilian municipalities presented an index slightly above 0.5 . In order to explain such variations, we tested political and management variables with data from the Superior Electoral Tribunal (TSE) and the Brazilian Institute of Geography and Statistics (IBGE). It was observed for a set of different variables that the level of fiscal balance is related to levels of political competition and electoral participation, as well as to the educational degree of direct administration personnel in the analyzed municipalities.

Keywords: good governments; federalism; fiscal balance

\title{
Resumen
}

Federalismo y buenos gobiernos: un análisis político de la gestión fiscal de los municipios

Veinticinco años después de la promulgación de la Constitución de 1988, la cual inauguró un nuevo nivel de relaciones intergubernamentales en Brasil, surge una pregunta: ¿este nuevo diseño institucional era capaz de fomentar buenos gobiernos a nivel de los municipios? Consideramos como buenos gobiernos las administraciones que presenten equilibrio fiscal en sus cuentas públicas. Se analizó el equilibrio fiscal de casi todos los municipios brasileños (2010) por medio del Índice Firjan de Gestión Fiscal (IFGF) publicado por la Federación de Industrias del Estado de Río de Janeiro (Firjan). Estos datos sugieren que los municipios presentan resultados fiscales considerablemente diferentes. A partir de una escala que varía de 0 a 1, detectamos municipios con una gestión fiscal crítica, con un índice cercano a 0 , y otros municipios con una excelente gestión fiscal, con un índice cercano a 1. En promedio, los municipios brasileños presentaron un índice ligeramente por encima de 0,5. Para explicar estas variaciones, hemos probado las variables políticas y de gestión con datos del Tribunal Superior Electoral (TSE) y del Instituto Brasileño de Geografía y Estadística (IBGE). Se observó a través de diferentes variables que el nivel de equilibrio fiscal se relaciona con los niveles de competencia política y de participación electoral, así como los niveles de formación del personal de la administración directa de los municipios analizados.

Palabras clave: buenos gobiernos; federalismo; equilibrio fiscal

\section{Résumé}

Fédéralisme et bons gouvernements: une analyse politique de la gestion budgétaire des communes

Vingt-cinq ans après la promulgation de la Constitution de 1988, qui a lancé un nouveau modèle de relations intergouvernementales au Brésil, une question peut être posée : cette nouvelle conception institutionnelle a-t-elle été capable de générer de bons gouvernements au niveau des communes ? Nous considérons comme de bons gouvernements les administrations présentant un équilibre budgétaire dans leurs comptes publics. Nous avons analysé l'équilibre budgétaire de presque toutes les communes brésiliennes en 2010, au moyen de l'Indice Firjan de gestion budgétaire (IFGF) publié par la Fédération des industries de l'état de Rio de Janeiro (Firjan). Ces données suggèrent un pays dans lequel les communes présentent des résultats fiscaux très variés. Sur une échelle allant de 0 à 1 , nous avons détecté des communes ayant une gestion critique, avec un indice proche de 0 , et $\mathrm{d}$ 'autres communes ayant une excellente gestion financière, avec un indice proche de 1 . En 
moyenne, les communes brésiliennes ont présenté un taux légèrement supérieur à 0,5. Pour expliquer cette variabilité, nous avons testé les variables politiques et de gestion qui ont été collectées auprès du Tribunal supérieur électoral (TSE) et de l'Institut brésilien de géographie et de statistique (IBGE). On a pu observer que le niveau de l'équilibre budgétaire est lié à des niveaux de concurrence politique et de participation électorale, ainsi qu'au niveau de formation du personnel de l'administration directe dans les communes analysées.

Mots-clés: bons gouvernements; fédéralisme; l'équilibre budgétaire

Artigo submetido à publicação em outubro de 2014 . Versão final aprovada em outubro de 2015. 